\title{
Relations Between Appraisals and Coping Schemas: Support for the Congruence Model
}

\author{
EDWARD J. PEACOCK and PAUL T.P. WONG, \\ Trent University and University of Toronto \\ GARY T. REKER, Trent University
}

\begin{abstract}
According to the cognitive-relational theory of stress, cognitive appraisal mediates coping efforts. However, only a small number of studies have examined appraisal-coping relations, and interpretation of the results is clouded by conceptual and methodological difficulties. The present study was designed to overcome some of these problems and to determine whether relations between appraisal and five coping schemas were consistent with predictions from the congruence model of effective coping. Participants in the study were 185 undergraduates in search of employment. Multiple regression analyses revealed that appraisals of challenge and controllability significantly predicted strategies representative of the problem-focussed schema, whereas, threat appraisals significantly predicted emotion-focussed coping. Furthermore, the existential coping schema was positively associated with appraising the situation as uncontrollable and negatively related to threat appraisal. The preventive schema was associated with appraisals of challenge and low threat. Spiritual coping was also significantly predicted by appraised uncontrollability. The results extend evidence of appraisal-coping relations to a broader range of coping strategies than previously investigated. Furthermore, the findings demonstrate the heuristic value of the cognitive schema approach to coping and of the congruence model in predicting appraisalcoping relations.
\end{abstract}

\section{Résumé}

Sclon la théorie cognitive-relationnelle du stress, l'appréciation cognitive oriente les efforts d'adaptation. Cependant, très peu d'études portent sur les relations entre l'appréciation et l'adaptation; qui plus est, des difficultés d'ordre conceptuel et méthodologique viennent occulter l'interprétation des résultats. L'étude susmentionnée a été conçue de manière à surmonter certaines de ces difficultés et à déterminer si les relations entre l'appréciation cognitive et cinq schémas d'adaptation correspondaient aux prédictions établies à partir du modèle de congruence de l'adaptation efficace. Les 185 participants étaient des étudiants du premier cycle à la recherche d'un emploi. Des analyses de régression multiple ont révélé que l'appréciation du défi et de la contrôlabilité permettait, dans une large mesure, de prédire l'utilisation de 
stratégies représcntatives du schéma axé sur les problèmes, tandis que l'appréciation de la menace permettait de prédire, de façon non moins négligeable, l'adaptation axée sur les émotions. Par ailleurs, le schéma d'adaptation existentielle était associé positivement à l'évaluation de la situation jugée incontrôlable et corrélé négativement à l'appréciation de la menace. Le schéma préventif était associé à l'appréciation du défi et à une menace de faible intensité.

L'appréciation de situations jugées incontrôlables permettait largement de prédire l'adaptation spirituelle. Les résultats obtenus montrent que les relations entre appréciation cognitive et adaptation s'appliquent à un éventail de stratégies d'adaptation plus large que celui sur lequel les recherches ont porté jusqu'ici. De plus, ils démontrent la valeur heuristique de l'approche d'adaptation fondée sur le schéma cognitif et du modèle de congruence dans l'établissement de prédictions concernant les relations entre l'appréciation cognitive et l'adaptation.

Appraisal is a central concept in the cognitive-relational theory of stress proposed by Richard Lazarus and his colleagues (Lazarus, 1966; Lazarus \& Launier, 1978; Lazarus \& Folkman, 1984). According to this view, primary appraisal is concerned with the relevance of situations with respect to one's well-being. A situation may be judged as being irrelevant, benign, or stressful. Stressful situations are appraised as taxing or exceeding one's coping resources and involving harm/loss, threat or challenge. Secondary appraisal is regarded as the assessment of coping options available for managing a given stressful encounter.

Coping efforts, according to Lazarus \& Folkman (1984), involve the cognitive and behavioural strategies used to manage specific stressful person-environment transactions. This approach emphasizes that coping is a process that is mediated by both primary and secondary appraisal. Coping is expected to be consistent with appraisal. For example, problem-focussed coping is predicted for situations appraised as changeable or controllable, whereas emotion-focussed coping is expected for situations appraised as unchangeable (Folkman and Lazarus, 1980). Also, it has been claimed that coping outcomes depend on the goodness of fit between appraisals and coping, as well as between what actually happens in the situation and how it is perceived (Folkman, Schaefer, \& Lazarus, 1979; Lazarus \& Folkman, 1984). Thus, matching or congruence has been proposed as an important factor determining the effectiveness of coping.

We first examine previous evidence concerning the relation between appraisal and coping, as well as the conceptual and methodological limitations of prior studies. Then, we report a study designed to overcome some of these difficulties and to investigate a broader range of coping strategies. Specifically, several predictions from a congruence model of effective coping were examined. 


\section{Studies of Appraisal-Coping Relations}

Primary Appraisal. Several primary appraisal variables have been linked to differences in coping. Coping has been found to vary with: the level of a perceived threat (Folkman, Lazarus, Dunkel-Schetter, DeLongis, \& Gruen, 1986), the perceived stakes (Folkman \& Lazarus, 1985), the appraised difficulty (Folkman \& Lazarus, 1985), the perceived desirability and the perceived amount of change in the situation (Stone \& Neale, 1984). Basically, these findings show that the higher the appraisal scores, the higher the scores on one or more coping scales.

To our knowledge, only two published studies have provided evidence that different primary appraisals are associated with different types of coping. McCrae (1984) found that active problem-solving and viewing the situation positively were used more for challenges whereas faith, fatalism and wishful thinking were used more for threats and losses. Folkman et al. (1986) found that the type of coping used varied with different types of threats.

Secondary Appraisal. Several studies that have examined secondary appraisal and coping have focussed on situational control appraisals. Perceived control has been associated with increased problem-focussed coping for major life events (Forsythe \& Compas, 1987) and for a university examination (Folkman and Lazarus, 1985). However, control appraisals were unrelated to problem-focussed coping for daily problems (Forsythe \& Compas, 1987). Emotion-focussed coping was unrelated to control appraisals for either major life events or daily hassles (Forsythe \& Compas, 1987), but one study found that for daily problems, perceived control was negatively related to emotion-focussed coping (Stone and Neale, 1984). Perceived control in an examination setting was also associated with less emotion-focussed coping (Folkman and Lazarus, 1985).

Folkman and Lazarus (1980) found that episodes appraised as requiring acceptance were associated with higher levels of emotion-focussed, coping and episodes the person thought could be changed were associated with increased problem-focussed coping. This association between appraisal of the situation as changeable and problem-focussed coping has been replicated in several studies (Bachrach \& Zautra, 1985; Folkman et al., 1986; Vitaliano, Russo, Carr, Maiuro, \& Becker, 1985) but there have also been exceptions (e.g., Pychyl, Little, and Hoge, 1987).

There is evidence that these "changeable" or control appraisals are positively related to some types of emotion-focussed coping (e.g., self-blame, seeking social support, accepting responsibility; Pychyl et al., 1987; Vitaliano et al., 1985) but are negatively related to other types of emotion-focussed coping (e.g., distancing, wishful thinking; Pychyl et al, 1987). Further complicating the picture is the finding that secondary appraisal and coping vary with locus of control beliefs (Parkes, 1984).

Several conclusions can be drawn from previous studies of appraisalcoping relations. First, given the theoretical and practical importance of 
appraisal-coping relations, there has been surprisingly little systematic research dealing with this issue. Second, most of the studies tend to be exploratory in nature rather than testing specific theoretical predictions. Third, the most consistent finding is a positive relation between changeable or control appraisals and problem-focussed coping, but even this is dependent on the stressor studied. Finally, interpretation of some of the findings is difficult due to a number of conceptual and methodological problems, to which we now turn.

\section{Conceptual and Methodological Difficulties}

All but one of these appraisal-coping studies involved retrospective reports of appraisal and coping. Respondents recalled situations that occurred hours, days, or even months previously. The validity of such retrospective appraisals has been questioned (Krantz, 1983; Stone \& Neale, 1984). Individuals may be biased to recalling and reporting retrospective appraisals that are consistent with their coping behaviours. Also, individuals who are unable to recall their initial perception of the situation may respond on the basis of how they coped. Thus, the observed associations between appraisal and coping may have been inflated.

Another problem stems from an overlap between appraisal and coping. Although the issue of confounded measures has received considerable attention in other areas of stress research (Edwards \& Cooper, 1988; Dohrenwend \& Shrout, 1985; Kasl, 1983; Lazarus, DeLongis, Folkman, \& Gruen, 1985; Lazarus \& Folkman, 1984; Leventhal and Tomarken, 1987), this problem has been virtually ignored in studies of appraisal-coping relations. For example, in several studies (e.g. Lazarus \& Folkman, 1980; Folkman, et al., 1986; Vitaliano et al., 1985), respondents were asked about their acceptance of the situation both in appraisal and coping measures. Several other coping items were similar in wording to other secondary appraisal items utilized. Therefore, the observed relation between appraisal and coping is confounded by an overlap in appraisal and coping measures.

Another example of overlap between appraisal and coping is that the term reappraisal has been used to refer to both appraisal and cognitive coping. Lazarus \& Folkman (1984) consider reappraisal both as a revised appraisal and a type of cognitive coping, which is variously called coping centered appraisal, defensive reappraisal, and cognitive reappraisal. Folkman \& Lazarus (1985) acknowledge this confound by stating “...cognitive coping, or what we have sometimes referred to as defensive reappraisal, is difficult to disentangle from primary and secondary appraisal" (p. 167). They claim that the problem stems from the fact that these concepts "...are inherently fused" (p. 167).

An additional difficulty stems from the fact that coping categories often have been based on factor analytic results, and different factors have been identified across studies. This is the case even when the same coping measure 
has been utilized. For example, factor analyses of the Ways of Coping Checklist have resulted in five to eight scales (Folkman \& Lazarus, 1985; Folkman, et al., 1986; Pychyl, et al., 1987; Vitaliano et al., 1985). Although some similarly-named factors have been identified in different studies (e.g., planful problem solving), other factors have been unique to a particular study (e.g., self-control; Folkman et al., 1986). Even for similarly-named factors, the number and nature of items loading on each factor varies. Another problem is that factors are often not conceptually pure. For example, in one study (Folkman, Lazarus, Dunkel-Schetter, DeLongis, \& Gruen, 1986), an item relating to prayer loaded on a factor labeled positive reappraisal along with items dealing with personal change and doing something creative. Such problems make interpretation and comparison of coping scales difficult.

\section{The Present Study}

The present study was designed to overcome some of the conceptual and methodological difficulties outlined in the previous section and to seek support for a general congruence model of appraisal-coping relations. To avoid retrospective reports of appraisal and coping, this study investigated an anticipatory stressor; furthermore, respondents were asked to report their current appraisals and coping efforts.

To minimize the confound between appraisal and coping, we ensure that items used to measure these two constructs do not overlap in wording or conceptualization. Thus, primary appraisal items focus on the assessment of threat, challenge, and centrality (i.e., perceived importance with respect to one's well-being; Gruen, Folkman, \& Lazarus, 1988). Secondary appraisal items are concerned with the perception of controllability (Folkman, 1984). Coping items, on the other hand, are concerned with actual behavioural and cognitive strategies employed to manage the stressful situation.

In addition, the coping categories investigated in this study were derived from the cognitive schema analysis of coping (Wong \& Reker, 1983, 1985b). Within personality and social psychology, schemas are widely accepted as conceptual categories representing various aspects of the individual's personal and social worlds (Cantor, 1990; Cantor \& Kilhstrom, 1987). Generally, schemas are cognitive structures of generalized knowledge, based on past experience (Fiske \& Taylor, 1984). The relevance of schemas to coping has been recognized by several investigators. Janoff-Bulman (1989) has discussed the linkage betwecn coping strategies and schemas about the world following victimization. Beck \& Emery (1985) have argued that individuals faced with a threat rely on cognitive schemas to select coping strategies. However, this paper shows the relevance of the schema approach to classifying and predicting coping behaviour.

The schema approach represents a rational, normative view of the coping process. A number of different types of schemas have been identified previously, such as person schemas, self-schemas, and goal schemas (Fiske 
\& Taylor, 1984). Coping schemas are like goal schemas in the sense that the objective of coping is to reduce stress and resolve problems. Coping schemas are organized knowledge about what coping strategies are effective in different stressful situations. This means that when faced with a stressful situation people can utilize coping schemas to select appropriate coping strategies (Beck \& Emery, 1985). The schema incorporates cultural knowledge and past experience in similar situations. For example, university students have the social knowledge that ability and effort are necessary to achieve success in our society; furthermore, as a result of years of schooling experience, they have learned that instrumental strategies are generally effective for dealing with academic problems.

More specifically, coping schemas are viewed as containing knowledge regarding characteristics of situations, coping responses available, and the effectiveness of the coping responses for various situations. Each coping schema represents a fuzzy category of the coping strategies appropriate for a given type of situation. Together, various coping schemas constitute an individual's acquired knowledge of what works in what situations.

On the basis of this approach, we have identified five coping schemas. Each is viewed as uniquely suited for a common stressful situation. Two of these schemas correspond to the well-established distinction between problem-focussed and emotion-focussed coping (Lazarus \& Folkman, 1984). The problem-focussed schema consists of strategies that are most appropriate for stressful situations that are controllable or manageable. The emotion-focussed schema refers to strategies that are suitable primarily for emotional problems.

In addition to these two schemas, preventive coping is also important (Lazarus \& Launier, 1978; McGrath \& Beehr, 1990; Taylor \& Schneider, 1989). The preventive schema refers to strategies that deal with anticipated problems. Another coping schema involves existential acceptance and the development of a sense of personal meaning (Antonovsky, 1979, 1987; Frankl, 1969; Wong, 1991). The existential schema attempts to make sense of loss, suffering, hardship, and the conditions of life, thus rendering life more tolerable (Stephenson, \& Murphy, 1986, Wong, 1989, 1991). It is primarily concerned with philosophical, ontological problems. Finally, many individuals, especially those in later years, focus on the spiritual realm in managing stress (Koenig, George \& Siegler, 1988; Koenig, Kvale, \& Ferrel, 1988; Markides, Levin \& Ray, 1987). The spiritual schema focusses on the spiritual dimension and is most closely associated with situations perceived as humanly uncontrollable. Thus, the five schemas cover five major kinds of life stress-controllable situations, emotional problems, anticipated demands, existential problems, and uncontrollable situations. Each schema consists of a set of coping strategies that is assumed to be effective for a particular kind of life stress.

We propose that appraisals provide the mechanism for activating coping schemas. Given that each schema contains knowledge of situational characteristics, it follows that situational appraisal will activate the relevant 
schema. For example, appraisal of a situation as controllable is assumed to activate the problem-focussed schema. Different patterns of appraisal will activate different coping schemas. In any potentially stressful encounter an individual will assess what kind of stressful situation it is; once a judgement has been made about the situation (e.g., that it is controllable, threatening, etc.), the coping schema that contains the corresponding set of situational characteristics will be activated. Once a coping schema has been activated, the coping strategies most typical or representative of the coping schema will be selected. Although the importance of congnuence for effective coping has been recognized by others (Folkman, Schaefer, \& Lazarus, 1979; Forsythe and Compas, 1987; Lazarus \& Folkman, 1984), no underlying mechanism has been specified previously. The present schema approach provides the mechanism whereby appraisal activates coping schemas that match the situation.

In summary, our congruence model has two components: appraisal and coping schemas. Appraisal activates the coping schema relevant to a stressful situation and the schema determines the appropriate coping responses. Because the congruence model is a normative model, it predicts optimal coping when the individual is completely rational and has extensive cultural knowledge. In real life, people sometimes fall short of optimal coping because they may react emotionally without thinking through the problem, or they may respond habitually in a way that is not appropriate for the situation. Nevertheless, it seems reasonable to assume that normal functioning individuals tend to cope in a way that approximates the model. Therefore, we can predict, for a given situation, what type of appraisal and coping are likely to occur.

It is hypothesized that appraisal of the situation as controllable and challenging will activate the problem-focussed schema. Similar appraisals of an anticipated event are expected to activate the preventive schema. The appraisal of threat is hypothesized to invoke the emotion-focussed schema because threat is typically associated with emotional problems such as anxiety (Beck \& Emery, 1985; Endler \& Edwards, 1986). Appraisal of the situation as uncontrollable is expected to trigger existential and spiritual schemas; the extent each of these two schemas is activated will depend on the person's psychosocial history and belief systems.

The main objective of the present study was to determine whether support could be obtained for the predictions derived from the congruence model of coping. The stress investigated in this study was the prospect of future unemployment, and the respondents were a sample of undergraduates who were seeking summer employment.

The anticipatory stress of summer employment entails several problem areas, such as the present problem of job search and submitting applications, the emotional problem of worry about unemployment, the existential problem of the meaning of work, and also the problem of anticipating interviews, potential difficulties and possible rejection. The congruence model 
predicts that these different problem areas will all be appraised and appropriate coping schemas activated. Thus, the model predicts which coping schemas will be related to specific appraisal dimensions.

\section{METHOD \\ Subjects}

The participants in this study were $\mathbf{1 8 5}$ male and female undergraduate students at Trent University who were seeking summer employment at the time of the study. Their mean age was 21.6 years.

\section{Measures}

The Coping Inventory. A 57 item measure of coping, developed by Wong and Reker $(1983,1985 b)$ was utilized. The coping schema approach dictates that for each common life problem people have generalized knowledge of what coping strategies are appropriate. Having identified five major life problems (i.e., solvable, emotional, anticipated, existential, and uncontrollable), we began to use our generalized knowledge to select items from the literature and from our own research. The final sclection of 57 items is based on the consensual responses from 30 individuals acting as judges, as well as psychometric considerations. Each schema represents a range of coping strategies that are uniquely appropriate for a certain type of stressor. The problem-focussed schema includes strategies that are aimed at resolving an existing situational problem (e.g., Try various ways to change the situation.). The emotion-focussed schema encompasses strategies that are directed at regulating one's emotional reactions (e.g., Avoid thinking about the problem or things that are upsetting.). Preventive coping strategies are aimed at reducing the likelihood of anticipated problems (e.g., Plan/prepare for the future.). Existential coping is aimed at finding some positive purpose from harm and loss (e.g., Believe that there is meaning and purpose in the things that happen to me.). Spiritual coping employs spiritual beliefs and practices in dealing with life's problems (e.g., Seek help and direction from God.).

The response options for the items are on a five-point scale ranging from (1) "not at all" to (5) "a great amount". Instructions stated that subjects were to indicate the extent to which they used each strategy in coping with the prospect of being unable to obtain a suitable summer job.

Previous internal consistency estimates have shown that the five scales have satisfactory reliability. For example, in a study of 153 elderly coping with anticipatory stress, alphas were: $.91, .91, .75, .86$, and .93 for problemfocussed, emotion-focussed, preventive, existential, and spiritual schemas, respectively (Wong \& Reker, 1987).

There is evidence from several studies that supports the validity of this coping inventory. Job anxiety has been found to have a strong positive correlation with emotion-focussed coping and to have significant negative correlations with problem-focussed, preventive, and existential coping. Type 
A individuals have been found to score significantly higher on the problem-focussed scale than Type B individuals (Greenglass, 1988; Wong and Reker, 1985a). Preventive and existential coping have been found to be negatively associated with burnout scores and positively related to a quality of life measure based on social and cultural activities (Greenglass, Burke \& Ondrack, 1990). Additionally, depression scores have been found to be positively related to emotion-focussed coping and negatively correlated with preventive coping (Peacock, Wong, \& Reker, 1986). The instrument has also been able to detect coping differences between young offenders and control subjects; the young offenders reported more emotion-focussed coping but less problem-focussed and existential coping (Morris, 1986). Taken together, this evidence provides some initial support for the validity of this coping inventory.

Appraisal Items. Five items were generated to measure appraisals. Response formats "consisted of five-point Likert options ranging from (1) "not at all" to (5) "very much". Three items measured primary appraisals; these items related to threat (To what extent do you see the prospect of not finding a suitable summer job a threat?), challenge (To what extent do you see the prospect of not finding a suitable summer job as a challenge?), centrality (To what extent is your well-being dependent on finding a suitable summer job?). The remaining two items dealt with secondary appraisals; one of these focussed on controllability (To what extent do you think that finding a suitable summer job is dependent on factors under your own control, such as skills, effort, etc.?), and the other dealt with uncontrollability (To what extent do you think that finding a suitable summer job is dependent on factors uncontrollable by anyone?).

\section{Procedure}

Students were approached in their classes four to six weeks prior to the end of the academic session. Respondents were those volunteers who were seeking full-time summer employment. Instructions on the questionnaire requested respondents to indicate how they coped with the prospect of not obtaining a suitable summer job and, for the appraisal items, how they perceived the present summer employment situation. In addition, the questionnaire included other measures not relevant to the present paper.

\section{RESULTS}

Apprnisnl

The mean ratings of the appraisal dimensions on the five-point scales were: 28 (threat), 3.2 (challenge), 3.3 (centrality), 3.8 (controllable), and 2.0 (uncontrollable).

The intercorrelations among appraisal dimensions are shown in Table 1. It can be seen that although the appraisals were relatively independent, there were several significant intercorrelations. The largest correlation was between 
TABLE I

Intercorrelations Among Appraisals

\begin{tabular}{lcccc}
\hline Appraisal & 2 & 3 & 4 & 5 \\
\hline 1. Threat & $.20^{* *}$ & $.47^{* * *}$ & .04 & .07 \\
2. Challenge & & $.16^{*}$ & $.15^{*}$ & .04 \\
3. Centrality & & & $\cdots .02$ & .12 \\
4. Controllability & & & & .13 \\
5. Uncontrollability & & & & \\
\hline
\end{tabular}

${ }^{*} p<.05$, $^{* *} p<.01$, *** $p<.001$

threat and centrality. Challenge and controllability were significantly correlated. The controllability and uncontrollability appraisals appear to be relatively independent evaluations.

The positive relation between threat and challenge is consistent with previous findings showing that threat and challenge appraisals frequently occur together (Lazarus \& Folkman, 1984); both are likely to occur for an ambiguous future situation (Folkman \& Lazarus, 1985).

\section{Coping}

The five coping scales were found to have satisfactory internal reliability. The alpha coefficients were: $.80, .84, .75, .65, .92$, for problem-focussed, emotionfocussed, existential, preventive, and spiritual schemas, respectively.

Strategies from all five coping schemas were employed in dealing with the anticipated problem. As predicted, preventive coping was the most frequently reported schema $(M=3.4)$; this was followed by problem-focussed $(M=3.2)$, existential $(M=3.0)$, spiritual $(M=2.3)$, and emotion-focussed $(M=2.2)$ strategies. These findings show, in addition to the reporting of problem- and emotion-focussed coping, respondents frequently reported use of preventive, existential, and spiritual strategies.

The intercorrelations of the coping schemas are presented in Table 2. There are several significant correlations; the largest are those between problem-focussed, existential and preventive coping. Given that the respondents were dealing with an anticipated situation, the correlation between preventive and problem-focussed coping is not surprising. Overall, these findings suggest that overlap between the coping schemas is low to moderate.

\section{Relalions Between Appraisal And Coping}

The predicted relations between appraisals and coping schemas were examined using hierarchical multiple regression analyses in which appraisal variables were entered as predictors of coping. For each coping category, the appraisal variables specified as predictors by the congruence model were entered at step one of the regression analyses and the significance of these predictors were examined. At step two of the analyses, the remaining appraisal variables were entered, yielding a full regression model; the 
TABLE 2

Intercorrelations Among Coping Schemas

\begin{tabular}{lllll}
\hline Coping Categories & 2 & 3 & 4 & 5 \\
\hline 1. Problem-Focused & .02 & $.43^{* * *}$ & $.60^{* * *}$ & .12 \\
2. Emotion-Focussed & & .08 & $-.22^{* *}$ & $.16^{*}$ \\
3. Existential & & & $.48^{* * *}$ & $.33^{* * *}$ \\
4. Preventive & & & & .09 \\
5. Spiritual & & & & \\
\hline
\end{tabular}

${ }^{*} p<.05,{ }^{* *} p<.01,{ }^{* * *} p<.001$

increment in variance from step one to step two was examined to determine if the inclusion of the remaining appraisal variables accounted for significant variance beyond that at step one. Table 3 summarizes the results of these analyses.

$\Lambda$ s expected on the basis of the congruence model, challenge and controllability appraisals were significant predictors of problem-focussed coping, accounting for over $9 \%$ of the variance; the remaining appraisals did not add significantly to the prediction of problem-focussed coping. Also consistent with the congruence model, threat was the only significant predictor of emotion-focussed coping, accounting for approximately $13 \%$ of the variance. Although centrality $(r=.23, p<.01)$ and uncontrollability $(r=$ $.16, p<.05)$ had significant zero-order correlations with emotion-focussed coping, these did not account for significant variance beyond that predicted by threat. For existential coping, uncontrollability emerged as hypothesized as a significant predictor but it accounted for less than $3 \%$ of the variance. The inclusion of the remaining appraisals in the regression model resulted in a significant increment in variance (over $8 \%$ increase). Examination of the significance of the beta weights indicated that threat was the only significant appraisal in addition to uncontrollability; interestingly, threat was negatively related to existential coping. For preventive coping, challenge and controllability appraisals were entered at step 1. Although these variables accounted for significant variance in preventive coping (over 6\%), only the beta for challenge was significant. Thus, contrary to prediction, controllability was not significantly associated with preventive coping. In addition, the remaining appraisals cntered at step two resulted in a significant increment in variance. However, the beta weights indicated that only threat contributed significantly to this increment; similar to findings for existential coping, threat was negatively related to preventive coping. When spiritual coping was the criterion, uncontrollability emerged as hypothesized at step one as a significant predictor, accounting for approximately $6 \%$ of the variance. At step 2, the remaining appraisals did not result in a significant increment in variance.

Overall, the regression results indicated that for four of the five coping schernas the predictions from the congruence model were supported and for 
TABLE 3

Summary of Hierarchical Multiple Regression Analyses Predicting Coping from Appraisal

\begin{tabular}{|c|c|c|c|c|c|c|}
\hline Criterion & Step & Predictors & $R^{2}$ Change & $F$ Change & Beta & $r$ \\
\hline \multirow[t]{7}{*}{ Problem-Focussed } & I. & Challenge & & & $.24^{* *}$ & .26 \\
\hline & & Controllability & & & $.16^{*}$ & .19 \\
\hline & & & .094 & $9.04^{* 4 *}$ & & \\
\hline & 2. & Threat & & & -.08 & -.01 \\
\hline & & Centrality & & & .01 & .03 \\
\hline & & Uncontrollability & & & .08 & .05 \\
\hline & & & .011 & .71 & & \\
\hline \multirow[t]{7}{*}{ Emotion-Focussed } & 1. & Threat & & & $-36^{* * *}$ & .36 \\
\hline & & & .126 & $25.47^{* * *}$ & & \\
\hline & 2. & Challenge & & & -.03 & .06 \\
\hline & & Centrality & & & .09 & .23 \\
\hline & & Controllability & & & .04 & .03 \\
\hline & & Uncontrollability & & & .13 & .16 \\
\hline & & & .025 & 1.29 & & \\
\hline \multirow[t]{7}{*}{ Existential } & 1. & Uncontrollability & & & $.16^{*}$ & .16 \\
\hline & & & .025 & $4.48^{n}$ & & \\
\hline & 2. & Challenge & & & .11 & .06 \\
\hline & & Threat & & & $-.18^{*}$ & -.20 \\
\hline & & Centrality & & & -.13 & -.16 \\
\hline & & Controllability & & & .12 & .10 \\
\hline & & & .084 & $4.07^{* *}$ & & \\
\hline \multirow[t]{7}{*}{ Preventive } & 1. & Challenge & & & $.23^{* *}$ & .24 \\
\hline & & Controllability & & & .09 & .12 \\
\hline & & & .065 & $6.05^{4 *}$ & & \\
\hline & 2 & Threat & & & $-.17^{*}$ & -.14 \\
\hline & & Centrality & & & -.11 & -.12 \\
\hline & & Uncontrollability & & & .08 & .05 \\
\hline & & & .057 & $3.7^{*}$ & & \\
\hline \multirow[t]{7}{*}{ Spiritual } & 1. & Uncontrollability & & & .24 & .24 \\
\hline & & & .058 & $10.85^{* *}$ & & \\
\hline & 2. & Challenge & & & .05 & .05 \\
\hline & & Threat & & & .08 & .04 \\
\hline & & Centrality & & & -.16 & -.08 \\
\hline & & Controllability & & & .06 & .03 \\
\hline & & & .025 & 1.18 & & \\
\hline
\end{tabular}

${ }^{*} p<.05,{ }^{* *} p<.01,{ }^{* * *} p<.001$

the fifth coping schema partial support was obtained. In addition, threat appraisals were independently related to variance in existential and preventive coping.

\section{DISCUSSION}

This study extends knowledge of appraisal and coping in several ways. First, in addition to linking appraisal to problem- and emotion-focussed coping, 
this study extended appraisal-coping relations to preventive, existential and spiritual coping. These findings of appraisal-coping relations are especially noteworthy because this study avoided retrospective reports and reduced content overlap between appraisal and coping measures. Second, the appraisal-coping relations obtained were highly consistent with predictions from the congruence model. Third, several relations observed in previous studies of stressful past events were replicated and extended to an anticipatory stressor.

Primary appraisals of threat and challenge were associated with different coping strategies. As predicted from the congruence model, challenge appraisals were associated with higher levels of problem-focussed and preventive coping, whereas threat appraisals were related to increased emotion-focussed coping. Threat appraisals were also negatively related to preventive and existential coping. These results are consistent with McCrae's (1984) findings for past stressful events. Clearly, threat and challenge appraisals are associated with qualitatively different coping strategies.

Centrality was correlated with emotional and existential coping, but not independently of threat. Nevertheless, we regard centrality as an important component of primary appraisal. Centrality reflects the extent to which important goals, beliefs and commitments are engaged (Cruen, Folkman, \& Lazarus, 1988). Threat and challenge, on the other hand, focus on the anticipated outcome; threat appraisals represents an expectation of harm or loss and associated negative emotions, whereas challenge appraisals reflect expectations of mastery and accompanying positive emotions (Lazarus \& Folkman, 1984). Across a variety of stressors, we have found that threat and centrality are the only appraisals that independently predict stressfulness (Peacock \& Wong, 1989).

Appraisals of controllability and uncontrollability were also related to coping in a manner consistent with the congruence model. Greater perceived controllability was associated with increased problem-focussed coping, replicating the only consistent appraisal-coping relation from previous studies (Bachrach \& Zautra, 1985; Folkman \& Lazarus, 1980; Folkman et al., 1986; Forsythe \& Compas, 1987; Vitaliano et al., 1985). Also as expected, perceived controllability was not significantly related to emotion-focussed coping, a finding that is in line with results of Forsythe \& Compas (1987) but not with those of Folkman and Lazarus (1985). In addition, controllability was not significantly related to either existential or spiritual coping. However, uncontrollability was significantly related to emotion-focussed, existential and spiritual coping but not problem-focussed coping. Contrary to prediction, controllability was not significantly related to preventive coping.

The questionnaire approach utilized in this study has certain advantages and limitations. An advantage is that it affords an opportunity for examining people's rational knowledge of stress and coping. A disadvantage is that responses may not accurately reflect the coping strategies actually utilized. 
As well, even though respondents were asked to report their current appraisals and coping strategies, their responses may have been based on what they recalled doing in the past. There is also a need to be cautious in interpreting the results because single-item appraisal measures were utilized. At the time of the study, there were no existing multi-item appraisal scales with known psychometric properties; since then, we have developed a multi-dimensional appraisal instrument (Peacock \& Wong, 1990). Finally, this study, like most others on appraisal and coping, is limited by its cross-sectional and correlational nature. There is a clear need for prospective studies which test alternative structural models of appraisal-coping relations.

In conclusion, the present study indicates that the congruence model of effective coping has considerable heuristic value because of its ability to predict appraisal-coping relations. In addition, the model has implications for stress outcomes because it predicts that congruence will be associated with more effective coping (Fisher, 1986; Folkman, Schaefer, \& Lazarus, 1979; Lazarus \& Folkman, 1984; Wong \& Reker, 1985b). The model is attractive because it requires only a few assumptions, yet generates a number of testable hypotheses. In this our initial investigation of the model, the emphasis was solely on appraisal-coping relations. The next obvious step is to investigate the relation between appraisal-coping congruence and subsequent outcomes.

Preparation of this paper was facilitated by a Social Sciences and Humanities Research Council of Canada Doctoral Fellowship awarded to the first author. The authors thank the Editor and three anonymous reviewers for their helpful comments on a previous version of this article.

Requests for reprints should be addressed to Paul T.I. Wong, Department of Psychology, Trent University, Peterborough, ON, Canada K9J $7 \mathrm{B8}$.

\section{References}

Antonovsky, A. (1979). Health, stress, and coping. San Francisco: Jossey-Bass.

Antonovsky, A. (1987). Unraveling the mystery of health: How people manage stress and stay well. San Francisco: Jossey-Bass.

Bachrach, K.M. \& Zautra, A.J. (1985). Coping with a community stressor: The threat of a hazardous waste facility. Journal of Ilealth and Social Behavior, 26, 127-144.

Beck, A.T., \& Emery, G. (1985). Anxicty disorders and phobias. New York: Basic Books.

Cantor, N. (1990). From thought to behavior: "Having" and "Doing" in the study of personality and cognition. American Psychologist, 45, 735-750.

Cantor, N., \& Kihlstrom, J.F. (1987). Personality and social intelligence.

Englewood Cliffs, NJ: Prentice-I lall.

Dohrenwend, B.S., \& Shrout, P.E. (1985). "Hassles" in the conceptualization and measurement of life stress variables. American Psychologist, 40, 780-785. 
Edwards, J.R., \& Cooper, C.I. (1988). Research in stress, coping, and health: Theoretical and methodological issues. $P_{\text {Sychological Medicine, }}$ 18, 15-20.

Fndler, N.S., \& Edwards, J.M. (1986, May). Stress and vulnerability related to anxiety disorders (Research Report \# 159). North York, Canada: York University, Department of Psychology.

Fisher, S. (1986). Stress and strategy. Hillsdale, NJ: Erlbaum.

Fiske, S.T., \& Taylor, S.F. (1984). Social cognition. Reading, MA: AddisonWesley.

Folkman, S., \& Lazarus, R.S. (1980). An analysis of coping in a middle-aged community sample. Journal of Health and Social Behavior, 21, 219-239.

Folkman, S., \& Lazarus, R.S. (1985). If it changes it must be a process: A study of emotion and coping during three stages of a college examination. Journal of Personality and Social Psychology, 48, 150-170.

Folkman, S., Lazarus, R.S., Dunkel-Schetter, C., DeLongis, A., \& Gruen, R.J. (1986). Dynamics of a stressful encounter: Cognitive appraisal, coping, and encounter outcomes. Journal of Personality and Social Psychology, 50, 992-1003.

Folkman, S., Lazarus, R.S., Gruen, R.J., \& DeLongis, A. (1986). Appraisal, coping, health status and psychological symptoms. Journal of Personality and Social Psychology, 50, 571-579.

Folkman, S., Schaefer, C., \& Lazarus, R.S. (1979). Cognitive processes as mediators of stress and coping. In V. Hamilton \& D.M. Warburton (Eds.), Human stress and cognition: An information-processing approach (pp. 265-298). I.ondon: Wiley.

Forsythe, C.J., \& Compas, B.E. (1987). Interaction of cognitive appraisals of stressful events and coping: Testing the goodness of fit hypothesis. Cognitive Therapy and Research, 11, 473-485.

Frankl, V. (1969). The will to meaning. Cleveland: World Publishing.

Greenglass, E.R. (1988). Type $A$ behaviour and coping strategies in female and male supervisors. Applied Psychology: An International Review, 37, 271-288.

Greenglass, E.R., \& Burke, R.J., \& Ondrack, M. (1990). A gender-role perspective of coping and burnout. Applied Psychology: An International Review, 39, 5-27.

Gruen, R.S., Folkman, S., \& Lazarus, R.S. (1988). Centrality and individual differences in the meaning of daily hassles. Journal of Personality, 56, 743-762.

Janoff-Bulman, R. (1989). Assumptive worlds and the stress of traumatic events: Applications of the schema construct. Social Cognition, 7, 11.3-138.

Kasl, S.V. (1983). I'ursuing the link between stressful life experiences and disease: A time for reappraisal. In C.L. Cooper (Ed.) Stress research, New York: Wiley.

Koenig, I I.G., George, L.K., \& Siegler, I.C. (1988). The use of religion and other emotion-regulating coping strategies among older adults. The Gerontologist, 28, 303-310.

Koenig, H.G., Kvale, J.N., \& Ferrel, C. (1988). Religion and well-being in later life. The Gerontologist, $28,18-28$. 
Krantz, S.E. (1983). Cognitive appraisals and problem-directed coping: A prospective study of stress. Journal of Personality and Social Psychology, 44, 638-643.

Lazarus, R.S. (1966). Psychological stress and the coping process. New York: McGraw-I Iill.

Lazarus, R.S., \& Folkman, S. (1984). Stress, appraisal, and coping. New York: Springer.

Lazarus, R.S., \& Launier, R. (1978). Stress-related transactions between person and environment. In L.A. Pervin \& M. Lewis (Eds.), Perspectives in interactional psychology (pp. 287-327), New York: Plenum.

Lazarus, R.S., DeLongis, A., Folkman, S., \& Gruen, R. (1985). Stress and adaptational outcomes: The problem of confounded measures. American Psychologist, 40, 770-779.

Leventhal, H., \& Tomarken, A.J. (1987). Stress and illness: Perspectives from Health Psychology. In S.V. Kasl \& C.L. Cooper (Fds.) Stress and health: Issues in research methodology (pp. 27-55). Chichester: Wiley.

Markides, K.S., Levin, J.S., \& Ray, L.A. (1987). Religion, aging, and life satisfaction: An eight-year, three-wave longitudinal study. The Gerontologist, 27, 660-665.

McCrae, R.R. (1984). Situational determinants of coping responses: Loss, threat, and challenge. Journal of Personality and Social Psychology, 46, 919-928.

McGrath, J.E. \& Beehr, T.A. (1990). Time and the stress process: Some temporal issues in the conceptualization and measurement of stress. Stress Medicine, 6. 93-104.

Morris, P. (1986). Delinquency: An inability to cope effectively with life problems. Unpublished honors undergraduate thesis, Trent University.

Parkes, K.R. (1984). Locus of control, cognitive appraisal, and coping in stressful episodes. Iournal of Personality and Social Psychology, 46, 655-668.

Peacock, E.J., Wong, P.T.P., \& Reker, G.T. (1986, June). Appraisal and coping with the prospect of summer unemployment. Paper presented at the annual meeting of the Canadian Psychological Association, Toronto.

Peacock, E.J., \& Wong, P.T.P. (1989, August). 1 multidimensional approach to measuring stress appraisal. Paper presented at the annual meeting of the American Psychological Association, New Orleans.

Peacock, E.J., \& Wong, P.T.P. (1990). The Stress Appraisal Measure (SAM): A multidimensional approach to cognitive appraisal. Stress Medicine, 6 , 227-236.

Pychyl, T.A., Little, B.R., \& Hoge, R.D. (1987, June). Context, appraisal, and coping: Situational determinants of the coping response. Paper presented at the annual meeting of the Canadian I'sychological Association, Vancouver.

Stephenson, J.S., \& Murphy, D. (1986). Existential grief: The special case of the chronically ill and disabled. Death Studies, 10, 102-119.

Stone, A.A., \& Neale, J.M. (1984). A new measure of daily coping: Development and preliminary resuits. Journal of Personality and Social Psychology, 46, 892-906. 
Taylor, S.E., \& Schneider, S.K. (1989). Coping and the simulation of events. Social Cognition, 7, 174-194.

Vitaliano, I.I., Russo, J., Carr, J.E., Maiuro, R.D., \& Becker, J. (1985). The Ways of Coping Checklist: Revision and psychometric properties. Multivariate Behavional Research, 20, 3-26.

Wong, P.T.P. (1991). Existential versus causal attributions: The social perceiver as philosopher. In S. Zelen (Ed.), New models, new extensions of altribution throry (pp. 84-125). New York: Springer-Verlag.

Wong, P.T.I. (1989). Personal meaning and successful aging. Canadian Psychology, 30, 516-525.

Wong, I'.T.I'., \& Reker, G.T. (1983). Face validity of the Coping Inventory. Paper presented at the annual meeting of the Canadian Association on Gerontology, Moncton, Canada.

Wong, P.T.P., \& Reker, G.T.(1985a, June). Coping behavior of Type A individuals. Paper presented at the annual meeting of the Canadian Psychological Association, Halifax, Canada.

Wong, P.T.P., \& Reker, G.T. (1985b, November). Effective coping and health: $\Lambda$ matching model. A workshop given at the Canadian Gerontological $\Lambda$ ssociation Meeting, Vancouver, Canada.

Wong, I'T.P., \& Reker, G.T. (1987). Stress and coping in the clderly. Unpublished manuscript, Trent Unjversity, Peterborough, ON.

Submission January 21, 1991

Revision May 15, 399]

Acceptance August 9, 1991 